\title{
Detecção de Aethalion reticulatum (L., 1767) (Hemiptera: Aethalionidae) em alfavaca- cravo (Ocimum gratissimum L.) e observações sobre sua ocorrência
}

\author{
RANDO, J.S.S.*; LIMA, C.B. \\ Universidade Estadual do Norte do Paraná (UENP), Campus Luiz Meneghel, Departamento de Produção Vegetal, \\ CEP: 86360-000, Bandeirantes-Brasil *jael@ffalm.br
}

\begin{abstract}
RESUMO: O objetivo deste trabalho foi relatar a ocorrência da cigarrinha Aethalionidae em alfavacacravo (Ocimum gratissimum L.) no município de Bandeirantes-PR. Plantas com cerca de dois anos, na fase reprodutiva, com inflorescências, flores, frutos e sementes, serviram como fonte para a coleta de ninfas e adultos das cigarrinhas. Registrou-se em alfavaca-cravo a espécie Aethalion reticulatum e a interação com as formigas Camponotus rufipes e $C$. crassus.
\end{abstract}

Palavras-chave: Aethalionidae, cigarrinha das fruteiras, alfavaca

\begin{abstract}
Detection of Aethalion reticulatum (L., 1767) (Hemiptera: Aethalionidae) in clove basil (Ocimum gratissimum L.) and observations of its occurrence. The aim of this work was to report the occurrence of the leafhopper Aethalionidae in clove basil (Ocimum gratissimum) in Bandeirantes Municipality, Paraná State, Brazil. Plants around two years old, in the reproductive phase, presenting inflorescences, flowers, fruits and seeds, were used as source for collection of leafhopper nymphs and adults. In clove basil, the species Aethalion reticulatum was recorded, in addition to its interaction with the ants Camponotus rufipes and $C$. crassus.
\end{abstract}

Key words: Aethalionidae, leafhopper, clove basil

A espécie Ocimum gratissimumé subarbusto anual e aromático que floresce durante todo o ano, apresentando inflorescências terminais com flores pequenas e brancas nas extremidades das ramificações e frutos-semente com quatro aquênios (Ferri et al., 1981). Pertence a família Lamiaceae, conhecida popularmente como alfavaca-cravo, comumente utilizada na medicina popular em países da América do Sul e África. A espécie é grande produtora de óleo essencial com $70-80 \%$ de eugenol (Gupta, 1994; Lorenzi \& Matos, 2002), sendo importante fonte comercial de eugenol na Índia, onde vem sendo cultivada. A planta é bastante utilizada na medicina, indústria e agricultura em função das propriedades antifúngica, antibacteriana, antidiarréica, hipoglicemiante e antiinflamatória (Nwosu \& Okafor, 1995; Nakamura et al., 1999; Offiah \& Chikwendu, 1999; Aguiyi et al., 2000; Rabelo et al., 2003). Apresenta ainda, ação anti-séptica local (Nakamura et al., 1999), sendo utilizada como aromatizante bucal (Matos, 1998).

Aethalion reticulatum (L., 1767) (Hemiptera: Aethalionidae), conhecida como cigarrinha das fruteiras, dos pomares ou ainda dos pedúnculos, é inseto sugador cujos adultos medem em torno de $10 \mathrm{~mm}$ de comprimento, de cor marrom ferrugínea, nervuras das asas salientes e esverdeadas. Apresentam longevidade aproximada de dois meses. As posturas são superficiais, porém a substância coletérica que envolve os ovos é de cor pardacenta ou acinzentada, confundindose com a casca dos ramos ou galhos onde se encontram. As fêmeas colocam até 100 ovos nos ramos e pedúnculos dos frutos das plantas hospedeiras que permanecem 30 dias no período de incubação, durante o qual a fêmea fica protegendo a postura com o corpo. As ninfas possuem o corpo de coloração cinza com estrias vermelhas, permanecendo nesta fase em agregações durante 45 dias. 0 ciclo total se completa em 110 dias, com três gerações ao ano. O movimento rápido e lateral das ninfas e adultos é característica comum nessa espécie (Vieira, 2007). Tanto adultos quanto ninfas sugam a seiva da planta, prejudicando o desenvolvimento de frutos e brotações, podendo, em altas infestações, matar o hospedeiro (Gallo et al., 2002).

A ocorrência da cigarrinha tem sido 

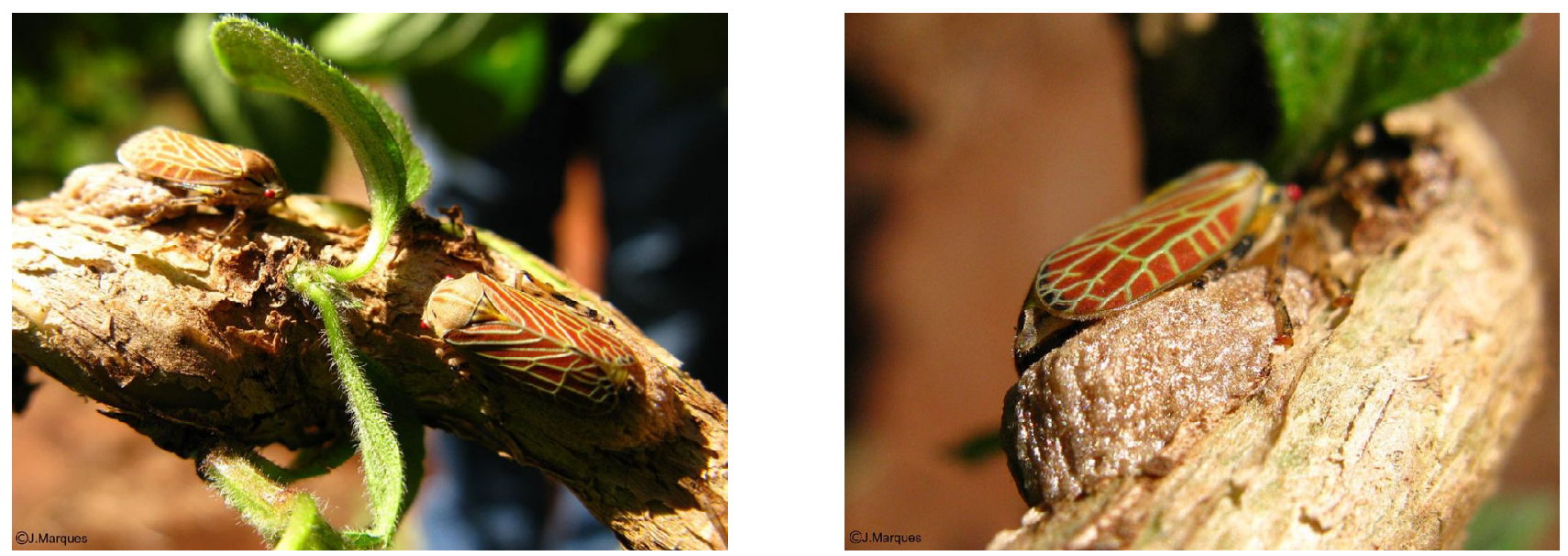

FIGURA 1. Fêmeas adultas de A. reticulatum sobre postura em ramos de O. gratissimum.

relatada nos estados: AM, BA, CE, ES, MG, PA, $P R, R J, R S, S C$ e SP em diversas plantas cultivadas e nativas, tais como acácia negra, algodoeiro, aroeira, cafeeiro, eucalipto e o gênero Citrus (Santana et al., 2005). A. reticulatum ataca pedúnculos de frutos de manga que atrofiam e caem (Nascimento \& Carvalho, 1998). Recentemente essa espécie foi constatada em plantios de Grevillea robusta em São Miguel Arcanjo, SP (Santana et al., 2005), mas não há referências sobre a ocorrência em $O$. gratissimum. Desse modo, o objetivo do trabalho foi relatar a ocorrência de $A$. reticulatum em plantas de alfavaca-cravo e a interação com formigas, no município de Bandeirantes-PR.

As observações foram efetuadas em plantas de alfavaca-cravo encontradas na Universidade Estadual do Norte do Paraná - Campus Luiz Meneghel (UENP-CLM), localizado em Bandeirantes, município da região Norte do Paraná, entre as coordenadas: Latitude $21^{\circ} 15^{\prime} S$, Longitude $50^{\circ} 23^{\prime} \mathrm{O}$ e altitude média de $440 \mathrm{~m}$. O tipo climático da região, segundo a classificação de Köepen, é o Cfa. As plantas de alfavaca-cravo com cerca de dois anos e, em média 1, 20 metros de altura localizamse próximas a regiões de cultivo de cana-de-açúcar. Encontravam-se na fase reprodutiva com inflorescências, flores, frutos e sementes. A exsicata foi identificada pela equipe do Museu Botânico de Curitiba-PR e incorporada ao herbário do jardim botânico da UENP-CLM sob o registro número 2200.

Constatou-se a ocorrência das cigarrinhas no mês de julho de 2008, época em que se coletaram adultos e ninfas, que foram levados ao laboratório para identificação (Borror \& DeLong, 1969; Costa Lima, 1942). Também foram coletadas formigas presentes nas agregações, que posteriormente foram enviadas para identificação no Instituto Biológico de São Paulo.

No mês de agosto foram feitas oito visitas na área de observação para avaliar as cigarrinhas e acompanhar seu hábito de desenvolvimento nas plantas de alfavaca-cravo. As visitas ocorreram a cada três dias, pela manhã entre 10 e 11 horas e à tarde entre 15 e 16 horas.

A ocorrência de cigarrinhas em alfavacacravo foi verificada inicialmente em planta que apresentou no decorrer das visitas sempre o maior número de agregações, bem como de adultos e ninfas. O número de agregações por planta nas primeiras avaliações era baixo, facilitando a contagem e o registro das informações, mas com o decorrer das visitas as agregações cresceram, dificultando essa prática. Os adultos, ninfas e posturas foram encontrados sempre na parte basal, junto à bifurcação dos ramos, que apresentavam em média $40 \mathrm{~mm}$ de circunferência, e que não recebiam luz solar de forma direta. As fêmeas, mesmo quando molestadas não abandonavam a postura (Figura 1); e as ninfas e os adultos agrupavam-se rapidamente após movimentação brusca da planta e dos ramos.

As cigarrinhas são insetos sugadores de planta e expelem via anal uma excreção líquida que contém açúcares como a frutose, glicose e sacarose, uma mistura complexa de lipídios, aminoácidos livres, amidos, minerais e vitamina B. Entretanto, a composição dessa excreção pode variar de acordo com a espécie e idade da planta hospedeira, a parte da planta onde o inseto sugador se alimenta, a quantidade de tempo que gasta se alimentando e pode ainda variar conforme a espécie sugadora (Fowler et al., 1991). Muitas espécies de formigas interagem com as cigarrinhas alimentando-se do líquido expelido por elas e em troca atuam defendendo-as de inimigos naturais (Morales, 2000; Stefani et al., 2000). Esse tipo de interação foi encontrado nesta pesquisa, com as espécies Camponotus rufipes (Fabr.) e C. Crassus (Mayr), que patrulhavam as agregações nas plantas e estimulavam com as antenas e tarsos, o abdome das cigarrinhas a fim de que estas expelissem as gotículas das quais se alimentam (Figura 2).

Dentre as várias formas com que o alimento vegetal pode ser disponibilizado para as formigas, as

Rev. Bras. PI. Med., Botucatu, v.12, n.2, p.239-242, 2010. 

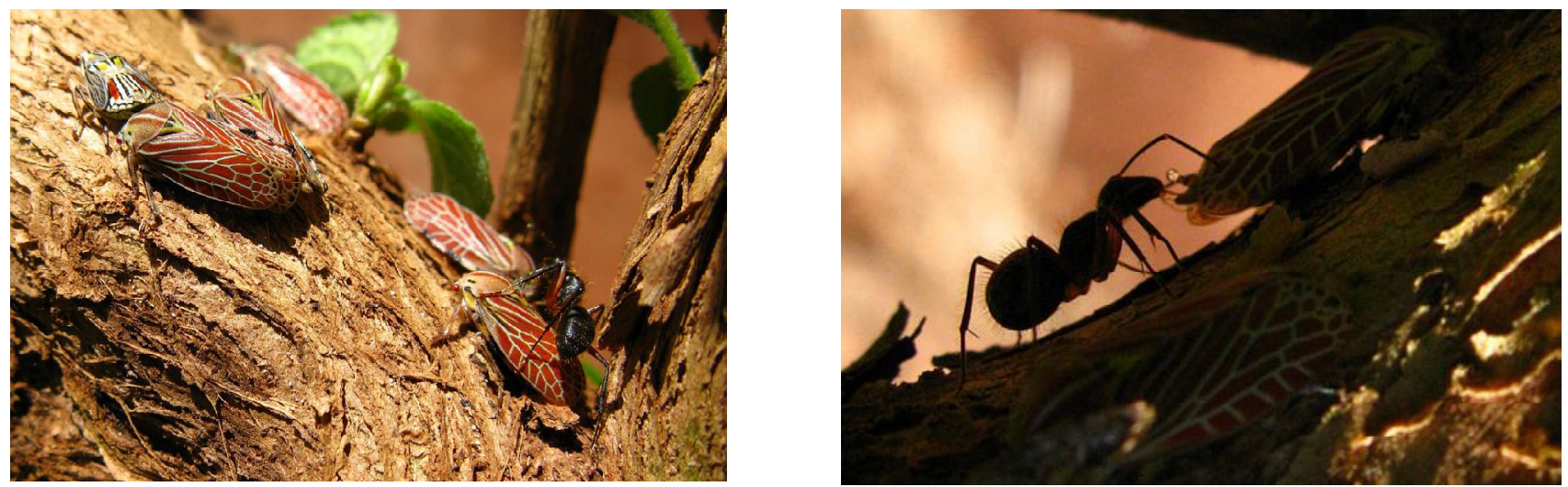

FIGURA 2. Formigas do gênero Camponotus alimentando-se das excreções das cigarrinhas, em ramos de $O$. gratisimum.

mais importantes são provavelmente nectários extraflorais (NEFs) e secreções de homópteros. As formigas ao permanecerem mais tempo sobre a planta explorando os NEFs e ao protegerem os homópteros de possíveis predadores, estariam também defendendo as plantas que abrigam estes recursos (Blüthgen et al., 2000).

As cigarrinhas A.reticulatum dependem das formigas para sobreviver, em Bauhinia forficata arbusto comum na região subtropical da America do Sul as agregações foram visitadas por seis espécies de formigas, sendo C.rufipes a mais comum (Fowler, 1992). De acordo com Leone (2006), houve predominância de formigas do gênero Camponotus quando associadas às cigarrinhas das famílias Membracidae e Aethalionidae em cultivo de feijão guandú. Camponotus rufipes, C. crassus e Zacryptocerus pusillus foram as formigas mais abundantes em Qualea multiflora, planta com porte arbustivo arbóreo típica do cerrado do Distrito Federal, sendo observadas visitando nectários extraflorais (Silva et al., 1996). Stefani et al. (2000) também relataram a predominância de espécies do gênero Camponotus associadas ao homóptero Enchenopa brasiliensis em plantas arbustivas de Solanum lycocarpum coletando exsudatos de ninfas e adultos desta cigarrinha.

Poucos são os estudos com artrópodes em plantas medicinais no Brasil, o que dificulta a adoção de medidas de manejo ecológico de insetos herbívoros (Dent, 1995). Em plantas medicinais cultivadas sob sistema orgânico $A$. reticulatum foi encontrada atacando plantas de boldo (Leite et al., 2006). Este trabalho registra pela primeira vez a ocorrência da cigarrinha $A$. reticulatum em Ocimum gratissimum.

\section{AGRADECIMENTO}

Agradecemos à Dra Ana Eugenia de Carvalho Campos, pesquisadora do Instituto Biológico de São Paulo, pela identificação das espécies de formigas.

\section{REFERÊNCIA}

AGUIYI, J.C.; OBI, C.I.; GANG, S.S. Hypoglycaemic activity of Ocimum gratissimum in rats. Fitoterapia, v.71, p.4446, 2000.

BORROR, D.J.; DeLONG, D.M. Introdução ao estudo dos insetos. Rio de Janeiro: USAID, 1969. 653p.

BLÜTHGEN, N. et al. How plants shape the ant community in the Amazonian rainforest canopy: the key role of extrafloral nectarines and homopteran honeydew. O ecologia, v.125, n.2, p.229-40, 2000.

COSTA LIMA, A. Insetos do Brasil - 3. Tomo: Homópteros. Escola Nacional de Agronomia (Série Didática n.4), 1942. $327 p$.

DENT, D.R. Integrated pest management. London: Chapman \& Hall, 1995. 356p.

FERRI, M.G.; MENEZES, N.L.; MONTEIRO-SCANAVACCA, W.R. Glossário ilustrado de botânica. São Paulo: Nobel, 1981. 197p.

FOWLER, H.G. Aethalzonzdae: functional equivalents of extrafloral nectaries in Bauhznza (Cesalpinionidea).

Anales de Biología, v.18, n.7, p.155-9, 1992.

FOWLER, H.G. et al. Ecologia nutricional de formigas. In: PANIZZI, A.R.; PARRA, J.R.P. (Eds.). Ecologia nutricional de insetos e suas implicações no manejo de pragas. São Paulo: Manole, 1991. p.131-23.

GALLO, D. et al. Entomologia agrícola. Piracicaba: FEALQ, 2002. 920p.

GUPTA, R. Basil (Ocimum spp.). G-15 gene banks for medicinal \& aromatic plants. Newsletter, n.5-6, p.1-3, 1994.

LEITE, G.L.D. et al. Fatores climáticos influenciam a abundância de artrópodes de plantas medicinais no Estado de Minas Gerais, Brasil. Revista Brasileira de Plantas Medicinais, v.8, n.3, p.43-51, 2006.

LEONE, A.R. Entomofauna associada ao feijão guandu [Cajanus cajan (L.) Millspaugh] no recôncavo baiano. 2006. 45p. Dissertação (Mestrado em Ciências Agrárias) - Centro de Ciências Agrárias e Ambientais. Universidade Federal da Bahia, Cruz das Almas.

LORENZI, H.; MATOS, F.J.A. Plantas medicinais no Brasil: nativas e exóticas cultivadas. Nova Odessa: Instituto Plantarum, 2002. 544p.

MATOS, F.J.A. Farmácias vivas: sistema de utilização de plantas medicinais projetado para pequenas 
comunidades. 3.ed. Fortaleza: EUFC, 1998. 220p.

MORALES, M.A. Mechanisms and density dependence of benefit in an ant-membracid mutualism. Ecology, v.81, n.2, p.482-9, 2000.

NAKAMURA, C.V. et al. Antibacterial activity of Ocimum gratissimum L. essential oil. Memórias do Instituto Oswaldo Cruz, v.94, n.5, p.675-8, 1999.

NASCIMENTO, A.S.; CARVALHO, R.S. Pragas da mangueira. In: BRAGA SOBRINHO, R.; CARDOSO, J.E.; FREIRE, F.C. (Eds). Pragas: de fruteiras tropicais de importância agroindustrial. Brasília: Embrapa-CNPAT, 1998. p.155-67.

NWOSU, M.O.; OKAFOR, J.I. Preliminary studies of the antifungal activities of some medicinal plants against Basidiobolus and some other pathogenic fungi. Mycoses, v.38, n.5-6, p.191-5, 1995.

OFFIAH, V.N.; CHIKWENDU, U.A. Antidiarrhoeal effects of Ocimum gratissimum leaf extract in experimental animals. Journal of Ethnopharmacology, v.68, p.32730, 1999.

RABELO, M. et al. Antinociceptive properties of the essential oil of Ocimum gratissimum L. (Labiatae) in mice. Brazilian Journal of Medical and Biological
Research, v.36, p.521-4, 2003.

SANTANA, D.L.Q. et al. Ocorrência de Aethalion reticulatum (Linnaeus, 1767) (Hemíptera: Aethalionodae) em Grevillea robusta. Boletim de Pesquisas Florestais, n.50, p.109-15, 2005.

SILVA, D.M.S.; COLEVATTI, R.G.; SANTOS, E.A. Visitação de formigas em nectários extraflorais de Qualea multiflora (Vochisiaceae) e seu potencial como agente anti-herbivoria. In: HENRIQUES, R.P.B.; COLLI, G.R.; HAY, J. V. (Eds.). Ecologia no cerrado. Brasília: UNB, 1996. p.2.

STEFANI, V.; SEBAIO, F.; DEL-CLARO, K. Desenvolvimento de Enchenopa brasiliensis Strumpel (Homóptera, Membracidae) em plantas de Solanum lycocarpum St.Hill. (Solanaceae) no cerrado e as formigas associadas. Revista Brasileira de Zoociências, v.2, n.1, p.21-30, 2000.

VIEIRA, C.U. et al. Interação entre Trigona spinipes Fabricius, 1793 (Hymenoptera: Apidade) e Aethalionidae reticulatum Linnaeus, 1767 (Hemíptera: Aethalionidae) em Mangifera indica (Anacardiaceae). Bioscience Journal, v.23, supl.1, p.10-3, 2007. 